\title{
Диазепам подавляет проявления агрессивного поведения крыс на моделях тревожно-депрессивного состояния, вызванного неонатальным действием ингибиторов дипепmидилnептидазы IV
}

\author{
Хлебникова Н.Н., Крупина Н.А.
}

Федеральное государственное бюджетное научное учреждение

«Научно-исследовательский институт общей патологии и патофизиологии».

125315, Москва, ул. Балтийская, д. 8

Актуальность. Расстройства эмочионально-мотивачионной сферы являются серьёзной проблемой в современном обществе. Причиной развития аффективных нарушений, патологической тревожности, повышенной агрессивности могут быть аверсивные события в раннем онтогенезе. Валидные модели таких заболеваний могут быть полезны в транслячионных исследованиях для изучения патофизиологических механизмов психических расстройств.

Цель. Оценить прогностическую валидность моделей тревожно-депрессивного состояния с повышенной агрессивностью, вызванного неонатальным действием ингибиторов дипептидилпептидазы-IV дипротина $A$ и ситаглиптина, путем исследования эффектов транквилизатора бензодиазепинового ряда диазепама, используемого в клинике при лечении симптомов агрессивности.

Методы. Дипротин А (2 мг/кг) или ситаглиптин (4 мг/кг) вводили крысятам в 5-19 постнатальные дни, внутрибрюшинно; контрольные животные получали физиологический раствор. Агрессивное поведение оченивали в тесте соииального взаимодействия в возрасте 2 месяиев дважды с интервалом в сутки: на фоне действия физиологического раствора и на фоне действия диазепама (1,25 мг/кг, внутрибрюшинно), которые вводили за 30 мин до тестирования. Результаты. На обеих моделях диазепам сходным образом купировал проявления стресс-провоцируемой агрессии у взрослых животных: снижал число и длительность агрессивных контактов. Длительность неагрессивных контактов на фоне действия диазепама была повышена.

Заключение. Подавление с помощью диазепама агрессивного поведения у крыс на разработанных моделях эмочионально-мотивационных нарушений с повышенной агрессивностью, вызванных неонатальным действием ингибиторов дипептидилпептидазы-IV, подтверждает их соответствие критерию прогностической валидности.

Ключевые слова: повышенная агрессия; модель; ингибиторы дипептидилпептидазы-IV; дипротин A; ситаглиптин; диазепам; крысы.

Для цитирования: Хлебникова Н.Н., Крупина Н.А. Диазепам подавляет проявления агрессивного поведения крыс на моделях тревожно-депрессивного состояния, вызванного неонатальным действием ингибиторов дипептидилпептидазы IV. Патогенез. 2019; 17(4): 50-56

DOI: $10.25557 / 2310-0435.2019 .04 .50-56$

Для корреспонденции: Хлебникова Надежда Николаевна, e-mail: nanikh@yandex.ru

Финансирование. Исследование не имело спонсорской поддержки.

Конфликт интересов. Авторы заявляют об отсутствии конфликта интересов.

Поступила: 20.09.2019

\section{Diazepam suppresses aggressive rat behavior in models of anxiety-depressive disorder induced by neonatal exposure to dipeptidyl peptidase IV inhibitors}

\author{
Khlebnikova N.N., Krupina N.A.
}

Institute of General Pathology and Pathophysiology,

Baltijskaya Str. 8, Moscow 125315, Russian Federation

Background. Disorders of the emotional-motivational sphere are a serious challenge the modern society is facing. Aversive events in early ontogenesis may underlie development of affective disorders, pathological anxiety, and increased aggression. Validated models of these diseases could be useful in translational research for studying the pathophysiology of mental disorders. The study aim was evaluating the predictive validity of models for the anxiety-depressive condition with increased aggressiveness induced by neonatal exposure to the dipeptidyl peptidase-IV inhibitors, diprotin A and sitagliptin. To this aim, the study focused on effects of the benzodiazepine tranquilizer, diazepam, that is used in clinic for the treatment of aggressiveness symptoms.

Materials and methods. Diprotin A (2 mg/kg) or sitagliptin (4 mg/kg) was administered to rat pups on postnatal days 5-19, intraperitoneally; control animals received saline. Aggressive behavior was evaluated using the Social Contact test in twomonth-old rats twice with a daily interval; first, against the background of saline and then against the background of diazepam $(1.25 \mathrm{mg} / \mathrm{kg}$, i.p.) administered 30 minutes prior to the test.

Results. In both models, diazepam similarly alleviated manifestations of stress-induced aggression in adult animals by decreasing the number of and the time spent in aggressive contacts and increasing the time spent in non-aggressive contacts. 
Conclusion. Suppression of aggressive behavior by diazepam confirms compliance of the developed models for emotionalmotivational disorders associated with increased aggression induced by the neonatal exposure to dipeptidyl peptidase-IV inhibitors with the criterion of predictive validity.

Keywords: increased aggression; model; dipeptidyl peptidase IV inhibitors; diprotin A; sitagliptin; diazepam; rats.

For citation: Khlebnikova N.N., Krupina N.A. [Diazepam suppresses aggressive rat behavior in models of anxiety-depressive disorder induced by neonatal exposure to dipeptidyl peptidase IV inhibitors]. Patogenez [Pathogenesis]. 2019; 17(4): 50-56 (in Russian)

DOI: $10.25557 / 2310-0435.2019 .04 .50-56$

For correspondence: Khlebnikova Nadezhda Nikolaevna, e-mail: nanikh@yandex.ru

Funding. The study had no sponsorship.

Conflict of interest. The authors declare no conflict of interest.

Received: 20.09.2019

\section{Введение}

В условиях современного общества значительная часть населения страдает от заболеваний, затрагивающих эмоционально-мотивационную сферу, к которым, в первую очередь, относятся различные нозологические формы депрессивных и тревожных расстройств [1]. Одним из ключевых факторов развития таких заболеваний может быть нарушение регуляции иммуновоспалительного ответа. Иммунная дизрегуляция может влиять на развитие нервной системы, приводя к изменениям нейрогенеза и синаптической передачи, что, в конечном итоге, проявляется нарушениями функционирования нейросетей в ЦНС [2]. Согласно другой гипотезе патогенез тревожно-депрессивных расстройств может быть связан с нейрохимическими процессами в медиаторных системах мозга и в системах регуляторных пептидов [3]. Клинические данные и экспериментальные исследования на животных подтверждают вовлеченность в регуляцию эмоций таких нейропептидов, как кортикотропин, вазопрессин, нейропептид $\mathrm{Y}$, нейропептид $\mathrm{S}$, окситоцин, вещество Р, галанин и другие [4].

В основе как иммунной, так и пептидергической гипотезы тревожно-депрессивных расстройств могут лежать дисфункции пролинспецифических пептидаз, в частности, дипептидилпептидазы IV (ДПП-IV, EC 3.4.14.5). ДПП-IV представляет собой мембраносвязанную эндопептидазу, расщепляющую пептиды с $\mathrm{N}$-конца, когда предпоследней аминокислотой является пролин или аланин. Ряд нейропептидов, регулирующих настроение и поведение, служит субстратом этой пептидазы. ДПП-IV обнаруживается на поверхности некоторых Т-лимфоцитов (CD26). Большое депрессивное расстройство сопровождается пониженной сывороточной активностью ДПП-IV [5], а у женщин с тревожно-фобическим расстройством понижен уровень CD26 в крови [6].

В наших исследованиях показано, что ингибиторы ДПП-IV, в условиях их введения крысятам в неонатальном периоде, вызывают в подростковом возрасте и у взрослых животных депрессивно- и тревожно-подобные нарушения поведения, сопровождаемые стресс-провоцируемой агрессивностью, ко- торые можно рассматривать как новые модели эмоционально-мотивационных расстройств [7]. Одним из критериев соответствия модели на животных её клиническому прообразу считают прогностическую валидность, которая отражает, в числе прочего, степень чувствительности модели к фармакологическим препаратам, эффективным при лечении заболевания в клинике [8]. В наших экспериментах классический трициклический антидепрессант имипрамин устранял симптомы депрессивности в поведении [9], а анксиолитик бензодиазепинового ряда диазепам нормализовал повышенный тревожно-фобический уровень [10]. В клинике бензодиазепины применяют для купирования агрессивных состояний, наряду с препаратами других фармакологических групп [11].

Цель данного исследования состояла в изучении влияния диазепама на стресс-провоцируемое агрессивное поведение взрослых крыс, вызванное действием ингибиторов ДПП-IV дипротина А и ситаглиптина в 5-19 постнатальные дни.

\section{Материалы и методы исследования}

Работа выполнена на белых крысах-самцах Вистар, выращенных в питомнике ФГБНУ «НИИОПП». Исследования проводили в соответствии с «Правилами надлежащей лабораторной практики в РФ», утвержденными приказом Министерства здравоохранения РФ от 01.04.2016 № 199н, и Директивой ЕС о защите животных, используемых в научных целях - EU Directive 2010/63/EU от 22.09.2010 г. что подтверждено протоколами этического комитета ФГБНУ «НИИОПП» № 1 от 12.05.2016 и № 5 от 30.03.2018.

Крыс содержали в стандартных условиях вивария с естественной сменой освещённости и свободным доступом к пище и воде.

Сразу после рождения каждой кормящей самке оставляли по 5 крысят мужского пола из разных пометов. День рождения считали нулевым постнатальным днем (ПНД0). Было проведено две серии экспериментов. В первой серии крысятам опытной группы вводили ингибитор ДПП-IV ситаглиптин (фосфат моногидрат, MB 523.32, Sigma-Aldrich, USA; $n=20$ ); во второй серии животные опытной группы получали дипротин А 
(H-Ile-Pro-Ile-OH, MB 341.45, Sigma-Aldrich, USA; $n=22)$. Доза ситаглиптина (4 мг/кг) соответствовала примерно половине максимальной суточной дозы для человека, составляющей 100 мг/сут, с учётом коэффициента пересчёта [12]. Доза дипротина А (2 мг/кг) была примерно эквимолярна дозе ситаглиптина. Препараты вводили крысятам в ПНД5-18 внутрибрюшинно один раз в сутки в объеме 0,1 мл на 10 г веса. Контрольным животным по той же схеме вводили физиологический раствор (ФР; $n=18$ и $n=19$ для первой и второй серии соответственно).

В возрасте 1 мес. крысят отделяли от матери и после двухдневного адаптационного периода оценивали эмоционально-мотивационную деятельность животных в батарее поведенческих тестов. Двигательную и исследовательскую активность измеряли в автоматизированном открытом поле («Opto-Varimex», Columbus instrument, США). Депрессивно-подобное поведение оценивали по снижению уровня жизненно-важных мотиваций (пищевой, питьевой, социального взаимодействия) и развитию ангедонии (тест потребления/ предпочтения сахарозы). Тревожность тестировали в приподнятом крестообразном лабиринте, а также с помощью специализированной шкалы для оценки тревожно-фобического уровня у крыс. Методики подробно описаны в статье [7].

Для оценки агрессивности использовали тест социального взаимодействия. Тестирование проводили в звукоизолированном помещении в незнакомой крысам клетке $(37,0 \times 57,0 \times 19,0$ см) при красном свете (7 Лк) с 10 до 14 часов. Предварительно животных содержали в клетках поодиночке в течение двух-трёх дней, так как в специальных исследованиях показано, что одиночное размещение способствует повышению числа социальных контактов [13]. Поведение оценивали для пары животных, поведение каждого животного отдельно не анализировали. Пары формировали из животных одной группы, незнакомых друг с другом и близких по массе тела. В течение 15 мин оценивали число и длительность активных неагрессивных и агрессивных социальных контактов. Неагрессивными контактами считали вынюхивание, социальный груминг, вскарабкивание на партнёра или подлезание под него, преследование без проявления агрессии. К агрессивным контактам относили преследование, переходящее в агрессивное взаимодействие, атаки/драки, агрессивный груминг. Для характеристики взаимодействия использовали показатели латентности, суммарного числа и времени активных неагрессивных и агрессивных контактов.

Обследование по всем тестам повторяли в возрасте 2 мес. За 30 мин до проведения теста зоосоциального взаимодействия крысам контрольных и опытных групп внутрибрюшинно вводили ФР. Поскольку агрессивность животных опытных групп оставалась повышенной, спустя сутки после первого тестирования крысы как опытных, так и контрольных групп получали анк- сиолитик бензодиазепинового ряда диазепам (препарат «Реланиум», «АО Варшавский фармацевтический завод Польфа», Польша), внутрибрюшинно, однократно, в дозе 1,25 мг/кг. Для достижения нужной дозы таблетку диазепама растворяли в требуемом объеме ФР. Через 30 мин после введения диазепама повторяли тест социального взаимодействия, подобрав новые пары незнакомых между собой животных.

Статистическую обработку данных проводили по алгоритмам программы «STATISTICA For Windows 7.0». Результаты проверки по тестам Колмогорова-Смирнова и Лиллиефорса не позволили принять гипотезу о нормальном характере распределения данных, поэтому для сравнительного анализа применяли непараметрический непарный двусторонний $\mathrm{U}$-критерий Манна-Уитни для независимых переменных с FDR поправкой на множественность сравнений. Принятый уровень значимости составлял 5\%, критический уровень значимости определяли методом FDR. Данные представлены в виде медианы и межквартиного размаха.

\section{Результаты исследования}

Результаты анализа поведения у крыс после неонатального введения дипротина А или ситаглиптина, опубликованные ранее [7], сведены в таблицу 1. В условиях введения крысятам ингибиторов ДПП-IV дипротина А и ситаглиптина на второй-третьей неделях постнатального развития у животных подросткового возраста развивалось смешанное тревожно-депрессивное состояние со стресс-провоцируемой агрессией, которое сохранялось у взрослых крыс. Действие дипротина А было более выраженным и устойчивым по сравнению с действием ситаглиптина.

Дипротин вызывал статистически значимое увеличение числа агрессивных контактов по сравнению с ФР, увеличение длительности агрессивных контактов не достигло уровня статистической значимости: $p=0,040$ при $p_{\text {крит }}=0,025$ (рис. 1). Под влиянием диазепама число и длительность агрессивных контактов статистически значимо снижались как в контрольной, так и в опытной группах по сравнению с соответствующими значениями в группах без введения диазепама. На фоне действия диазепама различие в числе и длительности агрессивных контактов между крысами групп «ФР + диазепам» и «Дипротин А + диазепам» не достигло уровня статистической значимости: по числу контактов $\mathrm{p}=0,040$, по длительности контактов $\mathrm{p}=0,043$ при $\mathrm{p}_{\text {крит }}=0,038$, то есть, диазепам подавлял повышенную агрессивность у крыс с неонатальным введением дипротина А.

Число неагрессивных социальных контактов в группе «Дипротин А + ФР» было снижено по сравнению с контрольной группой «ФР + ФР». Диазепам сам по себе не оказывал влияния на неагрессивное взаимодействие, однако увеличивал неагрессивное взаи- 
модействие у животных в группе «Дипротин А + диазепам» по сравнению с группой «ФР + диазепам» по показателю длительности контактов (рис. 1).

В серии с неонатальным действием ситаглиптина просматривалась тенденция к увеличению числа $(p=0,074)$ и длительности $\left(p=0,036\right.$ при $\left.p_{\text {крит }}=0,025\right)$ агрессивных контактов по сравнению с группой «ФР + ФР» (рис. 2), что свидетельствовало о менее выраженном проагрессивном действии ситаглиптина по сравнению с дипротином А. Диазепам сам по себе (группа «ФР + диазепам») в тенденции снижал число $\left(p=0,038\right.$ при $\left.p_{\text {крит }}=0,025\right)$ и длительность $(p=0,105)$ агрессивных контактов. Также диазепам снижал число и длительность агрессивных контактов у животных с неонатальным действием ситаглиптина.
Ситаглиптин не оказывал влияния на неагрессивное взаимодействие (рис. 2). Диазепам сам по себе снижал число неагрессивных контактов (группа «ФP + диазепам» по сравнению с группой «ФР +ФР»). В тенденции диазепам повышал длительность неагрессивных контактов у крыс с неонатальным действием ситаглиптина (группа «Ситаглиптин + диазепам» по сравнению с группой «Ситаглиптин $+\Phi \mathrm{P»;} p=0,046$ при $\left.\mathrm{p}_{\text {крит }}=0,025\right)$.

\section{Обсуждение}

В настоящем исследовании оба ингибитора ДППIV дипротин А и ситаглиптин в условиях их неонатального введения усиливали выраженность агрессивного
A

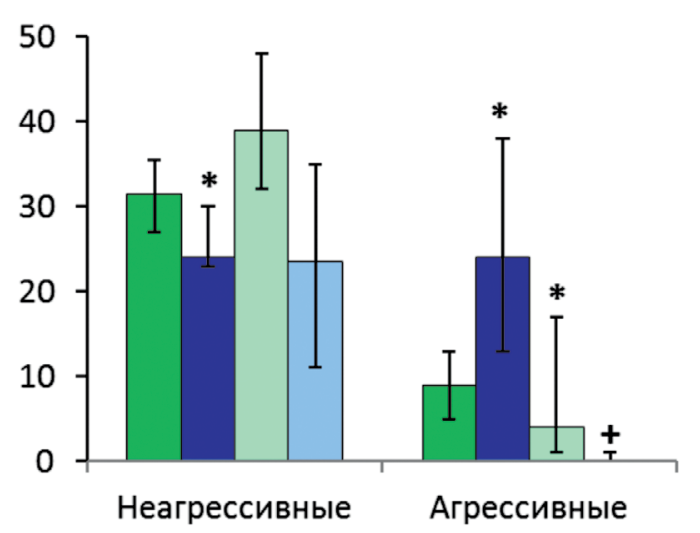

Б

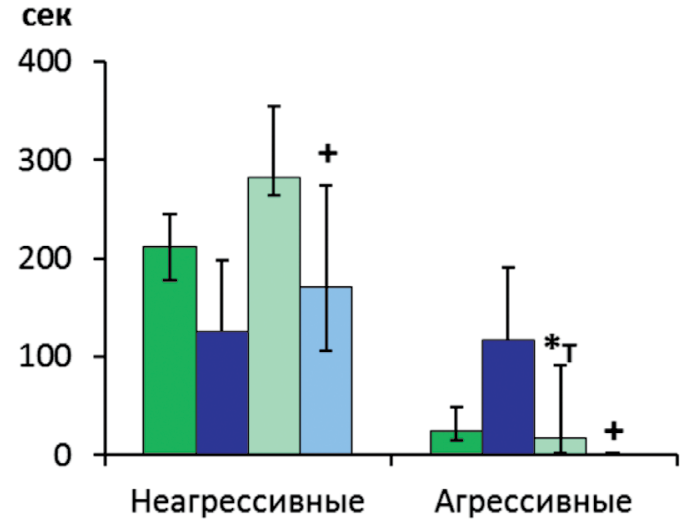

Рис. 1. Влияние диазепама на число (А) и длительность в секундах (Б) неагрессивных и агрессивных контактов в тесте социального взаимодействия у двухмесячных крыс с тревожно-депрессивным состоянием, вызванным действием дипротина А в ПНД 5-18 и отягощенным повышенной агрессивностью. Группы животных: тёмно-зелёные столбики - «ФР + ФР»; тёмно-синие столбики - «Дипротин А + ФР»; светло-зелёные столбики - «ФР + диазепам»; голубые столбики - «Дипротин $\mathrm{A}+$ диазепам». Статистическая значимость $\left(p<\mathrm{p}_{\text {крит }}\right)$ по сравнению с группой: * - «ФР + ФР»; + - «Дипротин А + ФР»; Т - указанная статистическая значимость на уровне тенденции.

Таблица 1

Сравнительный анализ нарушений поведения у крыс подросткового и взрослого возраста, подвергнутых действию ингибиторов ДПП-IV в 5-18 дни постнатального развития

\begin{tabular}{|c|c|c|c|c|}
\hline \multirow{2}{*}{ Показатели в поведенческих тестах } & \multicolumn{2}{|c|}{1 мec. } & \multicolumn{2}{|c|}{2 мес. } \\
\hline & Д & $\mathrm{C}$ & Д & $\mathrm{C}$ \\
\hline Двигательная активность & $=$ & $=$ & $=$ & $=$ \\
\hline «Поведенческое отчаяние» в тесте принудительного плавания & + & $=$ & + & $=$ \\
\hline $\begin{array}{l}\text { Чувствительность к положительному подкреплению в тесте на ангедо- } \\
\text { нию (потребление/предпочтение сахарозы) }\end{array}$ & + & + & + & $=$ \\
\hline Уровень одной из жизненно важных мотиваций - питьевой мотивации & + & + & + & + \\
\hline Неагрессивное социальное взаимодействие & + & $=$ & + & $=$ \\
\hline Тревожность в приподнятом крестообразном лабиринте & + & + & $=$ & $=$ \\
\hline Тревожность по шкале для оценки тревожно-фобического уровня у крыс & + & $=$ & $=$ & $=$ \\
\hline Агрессивное социальное взаимодействие & + & $=$ & + & + \\
\hline
\end{tabular}

Примечание. Д - дипротин А (2 мг/кг), С - ситаглиптин (4 мг/кг). + /= - есть/нет отличия от контроля. Голубые ячейки - депрессивно-подобное поведение (снижение предпочтения сахарозы при альтернативном выборе сахароза/вода, снижение уровня жизненно важной питьевой мотивации, «поведенческое отчаяние», уменьшение неагрессивных социальных контактов); жёлтые ячейки - повышенная тревожность, оранжевые ячейки - повышенная агрессивность. 
взаимодействия у крыс. Недавно в клинике получены свидетельства о наличии прямой корреляционной связи между ферментной активностью ДПП-IV в периферической крови и агрессивным поведением подростков с эмоциональными нарушениями [14]. Вовлеченность этой пептидазы в реализацию агрессивного поведения может определяться фермент-субстратным взаимодействием, поскольку её субстратами являются нейропептиды, участвующие в регуляции социального поведения и агрессивности (нейропептид Y, нейропептид $\mathrm{S}$, вещество P и некоторые другие). Помимо нейропептидов субстратами ДПП-IV могут быть прои противовоспалительные хемокины, гидролиз которых может приводить к появлению новых биоактивных молекул [15]. Цитокины, в дополнение к их традиционной роли в иммунном ответе, могут оказывать системное действие: выявлена их связь с такими поведенческими расстройствами, как тревога, депрессия, посттравматическое стрессовое расстройство [16]. Было также высказано предположение, что цитокины могут играть роль в нейробиологии агрессии, поскольку они экспрессируются в областях мозга, о которых уже известно, что они вовлечены в агрессивное поведение [17]. У людей такие черты личности, как гнев и враждебность, связаны с повышением уровня циркулирующего IL-6 [18]. Мыши, нокаутные по гену IL-6 (-/-), демонстрировали повышенную агрессию, а избыточная экспрессия IL-6 в мозге у нормальных животных усиливала аффилиативное поведение [19]. Мы полагаем, что аффективные нарушения у животных с неонатальным введением ингибиторов ДПП-IV могут быть связаны с изменениями, вызванными вмешательством в формирование этой ферментной системы в период её созревания в раннем постнатальном онтогенезе [20].

В нашей работе, как и ранее [7], обнаружено, что дипротин А оказывает более выраженное проагрессив- ное действие по сравнению с ситаглиптином на поведение крыс. Этот эффект можно связать с разными механизмами взаимодействия дипротина А и ситаглиптина с активным центром фермента ДПП-IV [21].

Диазепам уменьшал выраженность агрессивного поведения у животных на обеих моделях эмоционально-мотивационных расстройств. Этот факт согласуется с клиническими данными по использованию бензодиазепинов в психиатрической практике у больных с ажитацией и проявлениями агрессии [11]. В исследованиях на животных диазепам используют как препарат сравнения при скрининге веществ с потенциальным антиагрессивным действием [22]. Однако экспериментальные данные о влиянии диазепама на агрессивное поведение противоречивы: в ряде работ сообщается о снижении агрессивности у грызунов под действием бензодиазепинов; имеются свидетельства об отсутствии антиагрессивного эффекта или даже о повышении агрессивности в условиях введения бензодиазепинов (в том числе, диазепама) [22, 23]. Если сравнивать работы, в которых использовали близкие дозы и одинаковый способ введения диазепама, то разнонаправленное действие препарата, по-видимому, можно объяснить различной чувствительностью к бензодиазепинам субпопуляций ГАМК-ергических нейронов в стволе мозга, лимбических и корковых областях [24, 25] при активации той или иной структуры мозга в разных ситуациях, в том числе стрессогенных [23]. В нашей работе антиагрессивное действие диазепама прослеживалось у крыс с нарушенным эмоциональным фоном.

\section{Заключение}

В настоящем исследовании показано, что препарат бензодиазепинового ряда диазепам подавляет агрессивное поведение на двух моделях эмоциональ-
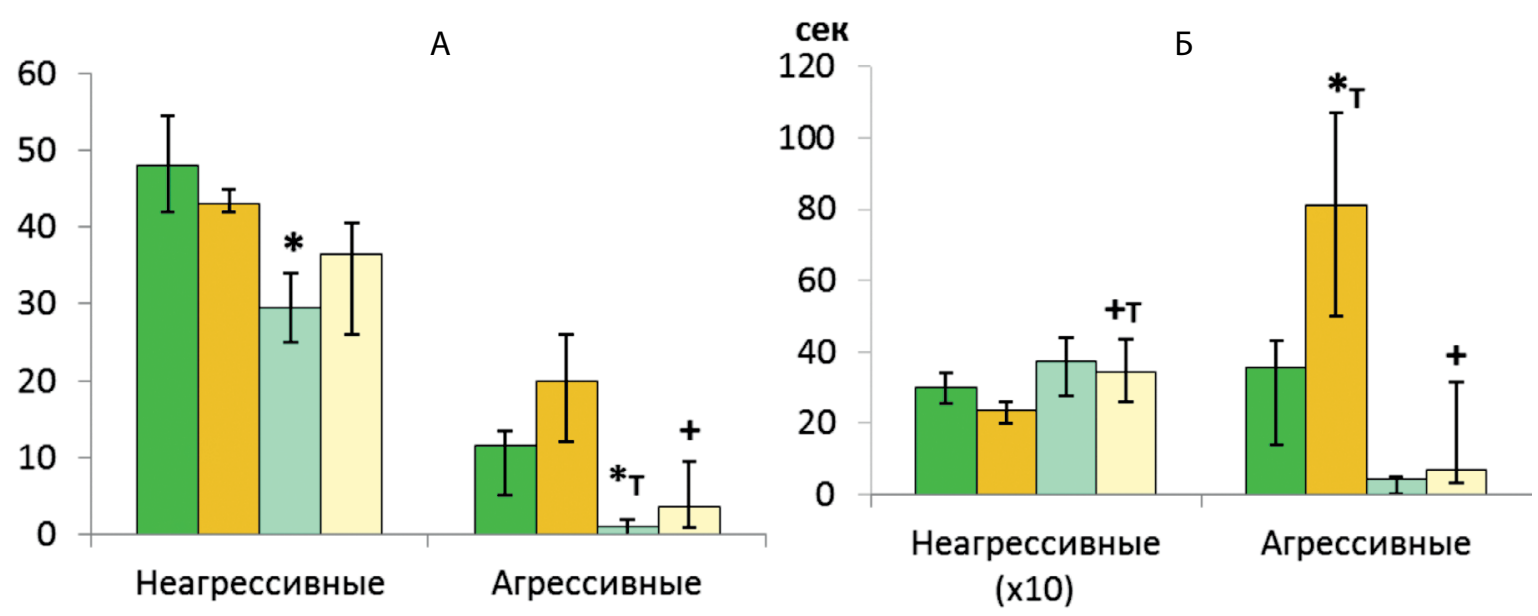

Рис. 2. Влияние диазепама на число (А) и длительность в секундах (Б) неагрессивных и агрессивных контактов в тесте социального взаимодействия у двухмесячных крыс с тревожно-депрессивным состоянием, отягощенным повышенной агрессивностью, вызванным действием ситаглиптина в ПНД 5-18. Группы животных: тёмно-зелёные столбики - «ФР + ФР»; жёлтые столбики - «Ситаглиптин + ФР»; светло-зелё-

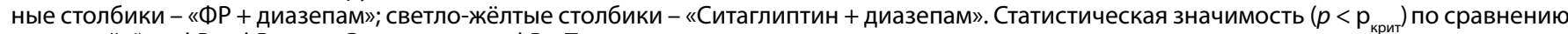
с группой: * - «ФР + ФР»; + - «Ситаглиптин + ФР»; Т - указанная статистическая значимость на уровне тенденции. 
но-мотивационных расстройств, индуцированных неонатальным действием ингибиторов ДПП-IV дипротина А и ситаглиптина. Данные свидетельствуют в пользу валидности этих моделей тревожно-депрессивных состояний, отягощенных стресс-провоцируемой агрессивностью.

\section{Список литературы}

1. Baxter A.J., Patton G., Scott K.M., Degenhardt L., Whiteford H.A. Global epidemiology of mental disorders: what are we missing? PLoS One. 2013; 8(6): e65514. DOI: 10.1371/journal.pone.0065514

2. Miller A.H., Raison C.L. The role of inflammation in depression: from evolutionary imperative to modern treatment target. Nat. Rev. Immunol. 2016; 16(1): 22-34. DOI: 10.1038/nri.2015.5

3. Hökfelt T., Barde S., Xu Z.D., Kuteeva E., Rüegg J., Le Maitre E., Risling M., Kehr J., Ihnatko R., Theodorsson E., Palkovits M., Deakin W., Bagdy G., Juhasz G., Prud'homme H.J., Mechawar N., Diaz-Heijtz R., Ögren S.O. Neuropeptide and small transmitter coexistence: fundamental studies and relevance to mental illness. Front. Neural. Circuits. 2018; 12: 106. DOI: 10.3389/fncir.2018.00106

4. Kormos V., Gaszner B. Role of neuropeptides in anxiety, stress, and depression: from animals to humans. Neuropeptides. 2013; 47(6): 401-419. DOI: $10.1016 /$ j.npep.2013.10.014

5. Maes M., De Meester I., Verkerk R., De Medts P., Wauters A., Vanhoof G., Vandoolaeghe E., Neels H., Scharpé S. Lower serum dipeptidyl peptidase IV activity in treatment resistant major depression: relationships with immune-inflammatory markers. Psychoneuroendocrinology 1997; 22(2): 65-78. DOI: 10.1016/S0306-4530(96)00040-6

6. Emanuele E., Minoretti P., Martinelli P., Pesenti S., Olivieri V., Aldeghi A., Politi P. Circulating levels of soluble CD26 are associated with phobic anxiety in women. Prog. Neuropsychopharmacol. Biol. Psychiatry 2006; 30(7): 1334-1336. DOI: 10.1016/j.pnpbp.2006.04.021

7. Krupina N.A., Khlebnikova N.N. Neonatal Exposure to the Dipeptidyl Peptidase-IV Inhibitors Diprotin A and Sitagliptin Induces Depression-Like Behavior, Anxiety, and Latent Aggression in Adolescent and Adult Rats. J. Behav. Brain Sci. 2016; 6(4): 167-183. DOI: 10.4236/jbbs.2016.64018

8. Belzung C., Lemoine M. Criteria of validity for animal models of psychiatric disorders: focus on anxiety disorders and depression. Biol. Mood Anxiety Disord. 2011; 1(1): 9. DOI: 10.1186/2045-5380-1-9

9. Хлебникова Н.Н., Крупина Н.А. Экспериментальное тревожно-депрессивное состояние у крыс, вызванное неонатальным действием ингибитора дипептидилпептидазы-IV дипротина А: эффекты имипрамина. Патологическая физиология и экспериментальная терапия. 2017; 61(4): 4-12. DOI: 10.25557/ IGPP.2017.4.8517

10. Крупина Н.А., Хлебникова Н.Н. Диазепам нормализует тревожность у крыс на модели тревожно-депрессивного состояния, вызванного введением дипротина А в первую постнатальную неделю развития. Патологическая физиология и экспериментальная терапия. 2018; 62(4): 4-11. DOI: 10.25557/0031-2991.2018.04.5-12

11. Alexander J., Tharyan P., Adams C., John T., Mol C., Philip J. Rapid tranquillisation of violent or agitated patients in a psychiatric emergency setting. Pragmatic randomised trial of intramuscular lorazepam v. haloperidol plus promethazine. Br. J. Psychiatry. 2004; 185: 63-69. DOI: $10.1192 /$ bjp. 185.1 .63

12. Гуськова Т.А. Доклиническое токсикологическое изучение лекарственных средств как гарантия безопасности проведения их клинических исследований. Токсикологический вестник. 2010; 5(104): 2-5.

13. Niesink R.J., van Ree J.M. Short-term isolation increases social interactions of male rats: a parametric analysis. Physiol. Behav. 1982; 29(5): 819-825. DOI: 10.1016/0031-9384(82)90331-6

14. Frenssen F., Croonenberghs J., Van den Steene H., Maes M. Prolyl endopeptidase and dipeptidyl peptidase IV are associated with externalizing and aggressive behaviors in normal and autistic adolescents. Life Sci. 2015; 136: 157-162. DOI: 10.1016/j.lfs.2015.07.003

15. Elmansi A.M., Awad M.E., Eisa N.H., Kondrikov D., Hussein K.A., Aguilar-Pérez A., Herberg S., Periyasamy-Thandavan S., Fulzele S., Hamrick M.W., McGee-Lawrence M.E., Isales C.M., Volkman B.F., Hill W.D. What doesn't kill you makes you stranger: Dipeptidyl peptidase-4 (CD26) proteolysis differentially modulates the activity of many peptide hormones and cytokines generating novel cryptic bioactive ligands. Pharmacol. Ther. 2019; 198: 90-108. DOI: 10.1016/j.pharmthera.2019.02.005

16. Dubois T., Reynaert C., Jacques D., Lepiece B., Patigny P., Zdanowicz N. Immunity and psychiatric disorders: variabilities of immunity biomarkers are they specific? Psychiatr. Danub. 2018; 30(Suppl 7): 447-451.

17. Provençal N., Suderman M.J., Vitaro F., Szyf M., Tremblay R.E. Childhood chronic physical aggression associates with adult cytokine levels in plasma. PLoS One. 2013; 8(7): e69481. DOI: 10.1371/journal. pone. 0069481

18. Marsland A.L., Prather A.A., Petersen K.L., Cohen S., Manuck S.B. Antagonistic characteristics are positively associated with inflammatory markers independently of trait negative emotionality. Brain Behav. Immun. 2008; 22(5): 753-761. DOI: 10.1016/j.bbi.2007.11.008

19. Alleva E., Cirulli F., Bianchi M., Bondiolotti G.P., Chiarotti F., De Acetis L., Panerai A.E. Behavioural characterization of interleukin-6 overexpressing or deficient mice during agonistic encounters. Eur. J. Neurosci. 1998; 10(12): 3664-3672. DOI: 10.1046/j.14609568.1998.00377.x

20. Kato T., Hama T., Nagatsu T., Kuzuya H., Sakakibara S. Changes of $\mathrm{X}$-prolyl dipeptidyl-aminopeptidase activity in developing rat brain. Experientia. 1979; 35(10): 1329-1330. DOI: 10.1007/bf01963989

21. Chakraborty C., Hsu M.J., Agoramoorthy G. Understanding the molecular dynamics of type-2 diabetes drug target DPP-4 and its interaction with Sitagliptin and inhibitor Diprotin-A. Cell. Biochem. Biophys. 2014.; 70(2): 907-922. DOI: 10.1007/s12013-014-9998-0

22. Tiwari O.P., Bhattamisra S.K.. Tripathi P.K., Singh P.N. Anti-aggressive activity of a standardized extract of Marsilea minuta Linn. in rodent models of aggression. Biosci. Trends 2010; 4(4): 190-194.

23. Молодавкин Г.М., Воронина Т.А., Алдармаа Ж., Мелетова О.К. Изменение антиагрессивного действия анксиолитиков под влиянием стресса. Экспериментальная и клиническая фармакология. 2004; 4: 3-6

24. Schwartzer J.J., Melloni R.H.Jr. Dopamine activity in the lateral anterior hypothalamus modulates AAS-induced aggression through D2 but not D5 receptors. Behav. Neurosci. 2010.; 124(5): 645-655. DOI: $10.1037 / \mathrm{a} 0020899$

25. Takahashi A., Quadros I.M., de Almeida R.M., Miczek K.A. Behavioral and pharmacogenetics of aggressive behavior. Curr. Top. Behav. Neurosci. 2012; 12: 73-138. DOI: 10.1007/7854_2011_191

\section{References}

1. Baxter A.J., Patton G., Scott K.M., Degenhardt L., Whiteford H.A. Global epidemiology of mental disorders: what are we missing? PLoS One. 2013; 8(6): e65514. DOI: 10.1371/journal.pone.0065514

2. Miller A.H., Raison C.L. The role of inflammation in depression: from evolutionary imperative to modern treatment target. Nat. Rev. Immunol. 2016; 16(1): 22-34. DOI: 10.1038/nri.2015.5

3. Hökfelt T., Barde S., Xu Z.D., Kuteeva E., Rüegg J., Le Maitre E., Risling M., Kehr J., Ihnatko R., Theodorsson E., Palkovits M., Deakin W., Bagdy G., Juhasz G., Prud'homme H.J., Mechawar N., Diaz-Heijtz R., Ögren S.O. Neuropeptide and small transmitter coexistence: fundamental studies and relevance to mental illness. Front. Neural. Circuits. 2018; 12: 106. DOI: 10.3389/fncir.2018.00106

4. Kormos V., Gaszner B. Role of neuropeptides in anxiety, stress, and depression: from animals to humans. Neuropeptides. 2013; 47(6): 401419. DOI: $10.1016 /$ j.npep.2013.10.014

5. Maes M., De Meester I., Verkerk R., De Medts P., Wauters A., Vanhoof G., Vandoolaeghe E., Neels H., Scharpé S. Lower serum dipeptidyl peptidase IV activity in treatment resistant major depression: relationships with immune-inflammatory markers. Psychoneuroendocrinology 1997; 22(2): 65-78. DOI: 10.1016/S0306-4530(96)00040-6

6. Emanuele E., Minoretti P., Martinelli P., Pesenti S., Olivieri V., Aldeghi A., Politi P. Circulating levels of soluble CD26 are associated with phobic anxiety in women. Prog. Neuropsychopharmacol. Biol. Psychiatry 2006; 30(7): 1334-1336. DOI: 10.1016/j.pnpbp.2006.04.021

7. Krupina N.A., Khlebnikova N.N. Neonatal Exposure to the Dipeptidyl Peptidase-IV Inhibitors Diprotin A and Sitagliptin Induces Depression-Like Behavior, Anxiety, and Latent Aggression in Adolescent and Adult Rats. J. Behav. Brain Sci. 2016; 6(4): 167-183. DOI: 10.4236/jbbs.2016.64018

8. Belzung C., Lemoine M. Criteria of validity for animal models of psychiatric disorders: focus on anxiety disorders and depression. Biol. Mood Anxiety Disord. 2011; 1(1): 9. DOI: 10.1186/2045-5380-1-9

9. Khlebnikova N.N., Krupina N.A. [Experimental anxiety-depressive state in rats caused by neonatal exposure to the inhibitor of dipep- 
tidyl peptidase IV, diprotin A: effects of imipramine]. Patologicheskaya fiziologiya i eksperimental'naya terapiya [Pathological physiology and experimental therapy]. 2017; 61(4): 4-12. DOI: 10.25557/ IGPP.2017.4.8517 (in Russian)

10. Krupina N.A., Khlebnikova N.N. [Diazepam normalizes anxiety in rats with experimental anxiety-depressive state induced by diprotin A in the first postnatal week]. Patologicheskaya fiziologiya $i$ eksperimental'naya terapiya [Pathological physiology and experimental therapy]. 2018; 62(4): 4-11. DOI: 10.25557/0031-2991.2018.04.5-12 (in Russian)

11. Alexander J., Tharyan P., Adams C., John T., Mol C., Philip J. Rapid tranquillisation of violent or agitated patients in a psychiatric emergency setting. Pragmatic randomised trial of intramuscular lorazepam v. haloperidol plus promethazine. Br. J. Psychiatry. 2004; 185: 63-69. DOI: 10.1192/bjp.185.1.63

12. Guskova T.A. [Preclinical Toxicological Study of Drugs as a Guarantee of Their Safe Clinical Investigations]. Toksikologicheskiy vestnik [Toxicological Bulletin]. 2010; 5(104): 2-5. (in Russian)

13. Niesink R.J., van Ree J.M. Short-term isolation increases social interactions of male rats: a parametric analysis. Physiol. Behav. 1982; 29(5): 819-825. DOI: 10.1016/0031-9384(82)90331-6

14. Frenssen F., Croonenberghs J., Van den Steene H., Maes M. Prolyl endopeptidase and dipeptidyl peptidase IV are associated with externalizing and aggressive behaviors in normal and autistic adolescents. Life Sci. 2015; 136: 157-162. DOI: 10.1016/j.lfs.2015.07.003

15. Elmansi A.M., Awad M.E., Eisa N.H., Kondrikov D., Hussein K.A., Aguilar-Pérez A., Herberg S., Periyasamy-Thandavan S., Fulzele S., Hamrick M.W., McGee-Lawrence M.E., Isales C.M., Volkman B.F., Hill W.D. What doesn't kill you makes you stranger: Dipeptidyl peptidase-4 (CD26) proteolysis differentially modulates the activity of many peptide hormones and cytokines generating novel cryptic bioactive ligands. Pharmacol. Ther. 2019; 198: 90-108. DOI: 10.1016/j.pharmthera.2019.02.005

16. Dubois T., Reynaert C., Jacques D., Lepiece B., Patigny P., Zdanowicz N. Immunity and psychiatric disorders: variabilities of immu- nity biomarkers are they specific? Psychiatr. Danub. 2018; 30(Suppl 7): 447-451.

17. Provençal N., Suderman M.J., Vitaro F., Szyf M., Tremblay R.E. Childhood chronic physical aggression associates with adult cytokine levels in plasma. PLoS One. 2013; 8(7): e69481. DOI: 10.1371/journal. pone. 0069481

18. Marsland A.L., Prather A.A., Petersen K.L., Cohen S., Manuck S.B. Antagonistic characteristics are positively associated with inflammatory markers independently of trait negative emotionality. Brain Behav. Immun. 2008; 22(5): 753-761. DOI: 10.1016/j.bbi.2007.11.008

19. Alleva E., Cirulli F., Bianchi M., Bondiolotti G.P., Chiarotti F., De Acetis L., Panerai A.E. Behavioural characterization of interleukin-6 overexpressing or deficient mice during agonistic encounters. Eur. J. Neurosci. 1998; 10(12): 3664-3672. DOI: 10.1046/j.1460-9568.1998.00377.x

20. Kato T., Hama T., Nagatsu T., Kuzuya H., Sakakibara S. Changes of $\mathrm{X}$-prolyl dipeptidyl-aminopeptidase activity in developing rat brain. Experientia. 1979; 35(10): 1329-1330. DOI: 10.1007/bf01963989

21. Chakraborty C., Hsu M.J., Agoramoorthy G. Understanding the molecular dynamics of type-2 diabetes drug target DPP-4 and its interaction with Sitagliptin and inhibitor Diprotin-A. Cell. Biochem. Biophys. 2014.; 70(2): 907-922. DOI: 10.1007/s12013-014-9998-0

22. Tiwari O.P., Bhattamisra S.K.. Tripathi P.K., Singh P.N. Anti-aggressive activity of a standardized extract of Marsilea minuta Linn. in rodent models of aggression. Biosci. Trends 2010; 4(4): 190-194.

23. Molodavkin G.M., Voronina T.A., Aldarmaa Zh., Meletova O.K. [Stress-induced alteration of the antiaggressive effect of anxiolytics]. Eksperimental'naya i klinicheskaya farmakologiya [Experimental and Clinical Pharmacology]. 2004; 4: 3-6

24. Schwartzer J.J., Melloni R.H.Jr. Dopamine activity in the lateral anterior hypothalamus modulates AAS-induced aggression through D2 but not D5 receptors. Behav. Neurosci. 2010.; 124(5): 645-655. DOI: 10.1037/a0020899

25. Takahashi A., Quadros I.M., de Almeida R.M., Miczek K.A. Behavioral and pharmacogenetics of aggressive behavior. Curr. Top. Behav. Neurosci. 2012; 12: 73-138. DOI: 10.1007/7854_2011_191

\section{Сведения об авторах:}

Хлебникова Надежда Николаевна - доктор биологических наук, ведущий научный сотрудник лаборатории общей патологии нервной системы Федерального государственного бюджетного научного учреждения «Научно-исследовательский институт общей патологии и патофизиологии»; https://orcid.org/0000-00020245-305X

Крупина Наталия Александровна - доктор биологических наук, главный научный сотрудник лаборатории общей патологии нервной системы Федерального государственного бюджетного научного учреждения «Научно-исследовательский институт общей патологии и патофизиологии»; https://orcid.org/0000-00022462-899X 